\title{
Using Activity Theory in system development for entire organisations: the case of the Swedish Trade Union Confederation
}

Sofie Pilemalm and Toomas Timpka

Linköping University Pre Print

Tweet

N.B.: When citing this work, cite the original article.

Original Publication:

Sofie Pilemalm and Toomas Timpka, Using Activity Theory in system development for entire organisations: the case of the Swedish Trade Union Confederation, 2002, International Journal of Human Resources Development and Management, (2), 3-4, 308-328.

Preprint available at: Linköping University Electronic Press

http://urn.kb.se/resolve?urn=urn:nbn:se:liu:diva-13488 
Paper V:

\title{
Using Activity Theory in System Development for Entire Organisations - the Case of the Swedish Trade Union Confederation
}

Sofie Pilemalm and Toomas Timpka

Submitted to: International Journal of Human Resources Development and Management

\begin{abstract}
Activity Theory has, in recent years, been criticised for not paying enough attention to the notion of individual versus collective subjects. It has also been pointed out that even though the Activity theoretical framework can beneficially be used in the initial development of information systems, actual attempts to apply it to concrete projects are only occasional. This study explores the use of Activity Theory in an organisational context where the subject is of marked collective nature, in an information system development project for the Swedish Trade Union Confederation (LO). Both implications of the study as regards the specific trade union application, and more general implications of applying Activity Theory to studies of entire organisations and for system development, are discussed.
\end{abstract}

\section{Keywords}

Activity Theory, organisational change, information system development, trade unions 
Using Activity Theory in System Development for Entire Organisations - the Case of the Swedish Trade Union Confederation 


\section{Introduction}

Developing for and introducing information systems to organisations is a complex task involving multiple interests and user groups. Too often systems are introduced without knowing the potential consequences they will have for the work context of the users, which means that unwanted consequences may occur, or that the systems are not used by or usable for the users $[1,2]$. Many system development methods have been criticised for ignoring the voice of the users and for focussing exclusively on isolated actions [3]. There are examples of significant system failures due to insufficient attention paid to organisational context, culture and environment when implementing information systems [4]. Activity Theory is a framework originating from late $19^{\text {th }}$ and early $20^{\text {th }}$ century Russian psychology, for studying human learning as a social interaction process [5]. Later the approach has expanded to other areas and is today multidisciplinary. Cultural-historical Activity Theory is framework that attempts to transcend micro- and macro-, material and mental aspects of observation and intervention in work redesign [5]. It has for instance been used for organisational learning, redesign of work tasks, and for analysing the implementation of new technology $[6,7,8]$. As regards systems development, it has been claimed that it can beneficially be used in, e.g. Human Computer Interaction and Computer Supported Co-operative Work, for capturing the context and collective aspects of human behaviour when interacting with computers $[3,9]$. Activity Theory takes a mediated activity as its prime unit of analysis and focuses on the whole context of users, including their activities, tasks and problems, as well as the historical past of present activities $[3,10]$. It has been claimed that information systems cannot be viewed from a technocratic deterministic standpoint, but have to be studied from an organisational, mediational perspective, for instance provided by symbolic interactionism and Activity Theory $[8,11]$. In this study, this perspective is taken, with the focus of bringing organisational issues and context to the system development process. The Cultural-historical Activity theoretical framework is extended and applied in the process for designing an information system to be used by shop stewards in the Swedish Trade Union Confederation (LO).

\section{The conceptual framework of macro-level Activity Theory}

In an organisational context, one version of Activity Theory in particular has received wide recognition; namely macro-level Activity Theory, in this study abbreviated as MAT. MAT attempts to study local activities against a macrolevel background, in which historical aspects and cultural resources common in the organisation or society at large influence the local activity. [12, 13]. In MAT, goal-oriented actions at the individual level are seen to move the overall 
activity towards its object [12] (Fig. 1). An action is thereby an immediate act performed by a single person and often occurring repeatedly in an activity. While activities are relatively stable, actions are performed on a short-time basis with an immediate goal. The status of activities is, however, not completely static but in continuous transition [5]. Another distinction not explicitly made in MAT but nonetheless important is between activities, actions and practices. Practices can be described as a cluster of actions that, together, make up part of the overall activity system and are partially responsible for fulfilling the object. An activity system is driven by a shared motive and directed towards a common object. The object is transformed into an outcome of the activity. This outcome is reached by using tools that can be both external, e.g. artefacts, and internal, e.g. symbols. The subjects, together, make up the activity community that is characterised by a certain division of labour and rules, e.g. in forms of norms [8]. The object can be of a material nature or less tangible like an idea [3]. Even the objects are in transition. They may be completely renewed or expanded, in which case, we speak about an expansive learning process [12]. A change in the object is often related to inner contradictions that are inherent in all activity systems. They may exist anywhere in the activity and frequently manifest themselves as disturbances or breakdowns [5]. Inner contradictions often call for a change in the activity. Changes are often described by referring to zones of proximal development, i.e. the transitional phase where one activity is successively modified or replaced by another. [12]. Technology is often involved in introducing changes. Changes may result in an expanded object, changed work tasks, rules and division of labour, or entirely new activities. [7]. Changes are most often not linear but cyclic $[12,14]$.

Critical standpoints have been raised in that even though Activity Theory can bring substantial benefits to the development of information systems, corresponding attempts to apply it are still occasional [9, 15]. MAT, however, has often been applied at a work task level, looking at individuals or groups performing their immediate tasks in a work context against a collective background [16, see also e.g. 8, 17, 18]. But when designing technology for entire organisations, it becomes important to complement the work task level with an overall organisational perspective, to connect networks of activity systems and try to foresee what effect specific design solutions may have on these systems. It has also been pointed out that the present versions of the theory do not direct enough attention to the distinction between individual and collective subjects (a group of subjects that to a significant extent share values and norms, and who reveals itself through collective activity rather than individual consciousness) [19]. 


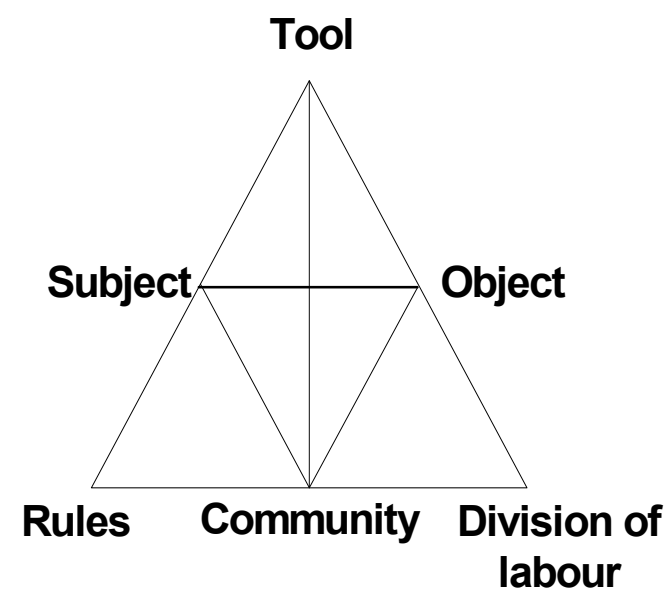

Figure 1. Model of MAT activity system. The subject directs its actions towards the object meditated by tools in a community with a certain labour division and rules.

\section{The legacy from UTOPIA - transforming trade unions by using information technology}

In recent years, trade unions world-wide have faced increasing constraints as societal and labour market developments have weakened their position and resulted in lower membership [20]. Further, they have had to deal with insufficient traditional training and information resources. The Swedish Trade Union Confederation (LO) has responded to these challenges by planning to implement information technology on a large scale in the union organisation. Based on a research tradition originating from, among several sources, the Swedish UTOPIA project in the 1980s [21], the Distance supported learning for Local Knowledge needs project (DLK) is intended to be the point of departure for major work with change [22]. It is a collaborative project involving LO, its affiliations, and researchers from Linköping University. One aim is to develop information technology based knowledge support for about 240000 LO shop stewards. Shop stewards are those who support their colleagues at the workplace and have part-time union assignments. As part of this, a prototype of an information system is being developed. The design work has a participatory character. The shop stewards themselves are supposed to formulate their needs for knowledge in day-to-day union work, and propose design solutions.

\section{Study aim and objectives}

The object of this study is to apply MAT to the context of designing an information system for shop stewards in a national trade union confederation. An extended MAT framework is introduced and used when analysing previously collected data on the organisation, within the framework of the DLK project, in order to provide empirically grounded hypotheses of how the planned design 
solution may influence the organisation. The specific aims of the study are two; to gather knowledge on how an information system may transform LO and union work, and to let the experience from this specific application generate knowledge on a more general level, in exploring how the extended MAT can be used in an organisational context and in system development. In detail, the ambition is to:

1. Describe an extended MAT representation and apply it to the existing overall activity system of shop stewards.

2. Apply the representation to overall activity systems taking place at other union organisational levels and connect these systems to shop stewards' activities in a network of activity systems.

3. Use the extended representation to discuss what changes the proposed design solution may impose on these networked activities.

\section{Methods}

Using MAT as a basis, Engeström [14] argues that expansive visibilisation of collective activity systems is a powerful methodology when dealing with transformation of work. He proposes four steps of expansive visibilisation, but for the present study, only the first three steps in the sequence were addressed. The steps include (1) data collection on everyday work practices, their contradictions and disturbances, (2) analysing this data and modelling the corresponding activity systems, (3) the design and implementation of partial novel solutions to the contradictions, and (4) the evaluation and revision of the solutions after studying their practical consequences.

\section{Visibilisation 1: Data collection}

According to Engeström's method, data collection is performed by sampling disturbances in naturalistic settings, e.g. by videotaping [14]. The empirical data used in this study is mainly collected from design meetings held in the project by the participating designers, who also acted as researchers and of whom one is the author of the present paper. Design work took place in a design group consisting of 9 user representatives, 1 educator, and 2 designers. The user representatives include both shop stewards at the local level and representatives from other layers in the organisation. The group works according to principles of Action Design, a system development method centred on active user 
representation, argumentation and documentation of design decisions [23]. Since the organisational phase in Action design greatly focuses on the present situation and its disturbances, it reflects Engeström' $\mathrm{s}$ first step of visibilisation. A difference is that the design work has a broader target group. Therefore, it is not enough to collect data from the design group's work but also from other user groups. For a period of approximately a year, the group held 11 meetings, mainly related to the organisational analysis and partly to the iterative prototyping phase. The set of primary additional data the designers in the group collected included:

1. A questionnaire sent out to union shop stewards. They where asked to describe their most recently experienced problem in union work, the consequences of the problem, how they solved the problem and potential remedies to the problem.

2. Literature studies on the union organisation.

3. Participatory observations at union affiliation offices.

4. Prototype evaluations and design practices performed with both shop stewards and representatives from other organisational levels in the union organisation.

\section{Visibilisation 2: Analysis and modelling}

Even the complementary material was thus collected and analysed by the participating designers. However, the results were continuously fed back to the design group, in order to form an agreed upon picture of the organisation, the shop stewards and their need for an information system. Quotations were taken directly from the empirical data but have been translated. The occurrence of dots indicates that something has been left out in the translation. According to Engeström's method, the present activity systems are modelled with a focus on tensions and contradictions. Then, an envisioned, future activity system is modelled on a general level [14]. This study follows the modelling procedure. However, due to its overall organisational perspective, the representations of activity systems are complemented with models of the mediation of the interpersonal relations in the union community, using the theoretical framework described by Petrovsky [24].

\section{An expanded representation of activity systems}

Activity systems are seen as contexts in which subjects, i.e. individuals or subgroups act and interact. However, the representation used in most present versions of MAT does not cover all aspects of activities. In particular, the nature 
of the subject with regard to collective aspects is not further specified. In modelling collective activities, interpersonal relations in communities are strongly related to the morals and values prevalent in the specific community [24]. In this context, a collective subject is a community of individuals where interpersonal relations are strongly mediated by the joint activities that are perceived to have a socially highly valuable and personally significant meaning. The individuals' interpersonal behaviour has its origin in the acceptance of one kind of influence and rejection of others depending on the nature of the mediating factors, i.e. the principles, ideals, and morals underpinning the joint activity. For this study, the union organisational culture was deemed to have significant impact on the nature of the collective subject. Therefore, the concept of subject in MAT was extended based on the nature and relative strength of social values in inter-personal relations (Fig. 2.):

Antisocial composite subject: The community is characterised by a high degree of mediation of interpersonal relations, but a reactionary, anti-emancipatory nature of the mediatory factors that militate against social progress.

Asocial association: The mediation of interpersonal relations by some joint activity in the group is low, with a low social value of these mediating factors still present. The interpersonal relations are determined by various asocial views and notions.

Diffuse group: There is almost an absence of mediation resulting from the absence of joint activity. In addition, the social value of the mediating factors is low, as is their influence on interpersonal relations.

Procollective association: There is a minimal degree of mediation from factors with high social value, which would have mediated interpersonal relations if the community had been based on a corresponding joint activity. The group processes are little influenced by advanced social values. The success of one individual does not determine the success of another.

Collective subject: The factors mediating interpersonal relations in the group are able to provide a maximum degree of mediation and social value. The high social significance of the mediatory factors has a definite influence on the interpersonal relations of the collective's members increasing their cohesion to a maximum possible degree. 


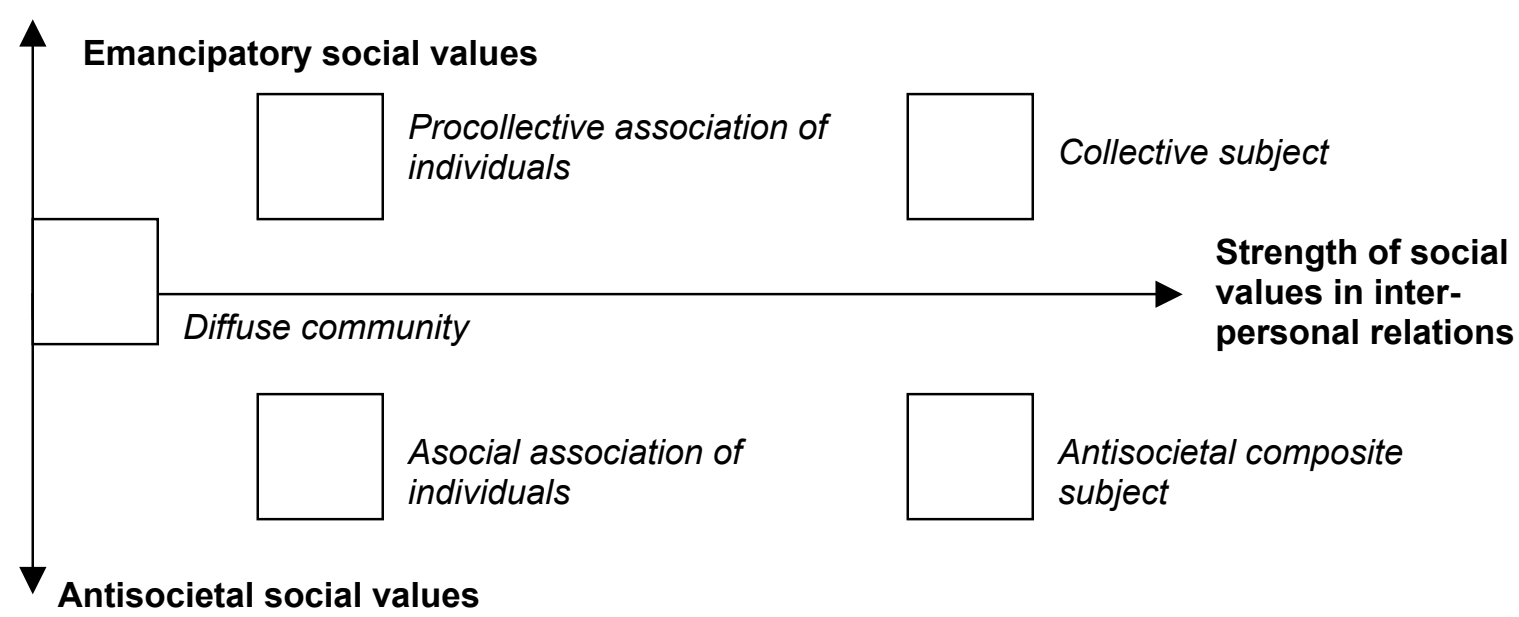

Figure 2. Communities of subjects with respect to the nature and strength of social values in interpersonal relations.

\section{Visibilisation 3 and 4: Design, implementation and revision}

According to Engeström's method, the practitioners participate in development activities in which they design practical solutions intended to function close to the constructed visionary models. The solutions are implemented and then revised after a period of evaluation [14]. In this study, the design step included the design of a prototype of an information system to support the redesign of shop stewards' work tasks. Also in this case, practitioners have actively participated in the design step, at design meetings and through prototype evaluations with different user groups. The major difference is that the second and third visibilisation steps have been carried out simultaneously. This is because the chosen design solution has a direct impact on the envisioned models, in that these visualise potential consequences of its implementation. The content and structure of the prototype reflects the needs of shop stewards, but also pays attention to organisational pre-requisites and constraints that emerge from the data analysis. The implementation part in this step, and the fourth step of visibilisation is not included in this study, which means that only hypothetical consequences of the system will be studied. Practical implementations and consequences will be part of future research. 


\section{Findings}

In this section the major findings are presented and used for analysis of shop stewards' work, the union organisation and its relation to an information system. The findings have been presented in more detail elsewhere, in the studies referred to $[22,25,26]$. The main activity system of shop stewards is summarised in Fig. 3. What was most evident from the analysis was how shop stewards work close to members, whose needs and rights are their immediate object of work. As a data excerpt shows:

The function of the work place organisation is to support the individual member...That is the main function of the work place organisation...the only function.

The tools shop stewards use include, e.g. information sources in forms of laws and agreements, and tools for communication. Communication and seeking support are almost exclusively vertical, to higher levels in the organisation. The division of labour is characterised by shop stewards sometimes working alone, sometimes together with the local club [25]. The shop stewards' immediate community is the workplace, which in its turn can be placed in the overall union affiliation community, or even the entire LO organisation. Rules strongly reflect Swedish union history and ideology as well as current strategies, e.g. solidarity and a simultaneous oppositional and collaborative relation to the employer. The shop stewards participating in the design work reported that they had become active unionists for ideological reasons. LO has traditionally held a strong position and been able to encourage its shop stewards not only to influence wage setting but also issues concerning a healthy work environment. The ideal outcome of shop stewards" work is, thereby, "the good working life" implemented at the workplace, i.e. satisfied members and a strong local union organisation [21]. The object of shop stewards' work is fulfilled by day-to-day practices. These, recurring in the questionnaire and at the design meetings, are multiple. The most important are formal negotiations, being an informant, personal conflict management, arguing for union values, and continuous knowledge acquisition [26]. 


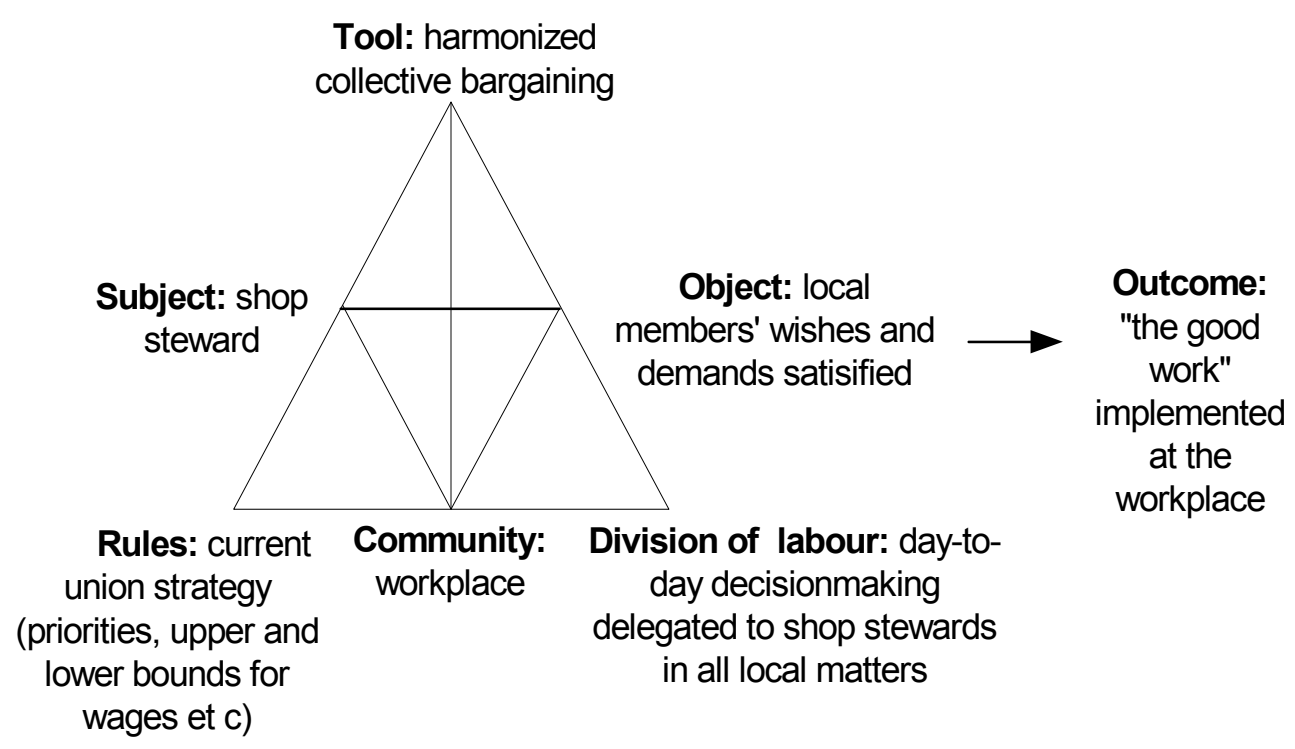

Figure 3. The overall activity system of local union work. Shop stewards are provided with extensive laws and agreements to be used in collective bargaining for satisfying the demands of members and to implement "the good working life".

The activity system of shop stewards is yet but one of an abundance making up the LO organisation. LO was found to be characterised by a hierarchical structure in which the levels have different functions and clearly defined spheres of action. Union affiliations are generally divided into the workplace level, sometimes including a local club, the sections, the departments and the affiliation offices [25]. Together these make up LO, an umbrella organisation consisting of 18 individual affiliations. Shop stewards perform the operative activities at the workplaces, directly targeted towards members. The local clubs and sections are intended to support this work. Departments have comprehensive administrative duties and handle, e.g. union training, member registration and unemployment benefit funds. Departments also deal with negotiations that cannot be settled at the club level. The affiliation offices negotiate at the central level, but are additionally responsible for overall decision-making, long-term strategic planning, and dealing with politics and societal issues [25].

\section{The procollective union}

The interpersonal relations of shop stewards in the activity system of union work can be characterised in terms of a procollective association of individuals (Fig. 2.). There is a minimal degree of mediation in local activities from factors with high social value for union work. There is also a low level of joint activity, i.e. the fact that the success of one shop steward does not determine the success of 
another. One explanation for the circumstances underlying these observations can be that the activity system of shop stewards and those related to other organisational functions form a complex network of interrelated activities. Within and between these activities, a variety of social values can be found. It became evident that the LO organisational structure enforces certain kinds of inner contradictions that continuously result in breakdowns, both in shop stewards' activities and in the entire organisation. The contradictions found in the analysis relate to:

- The transitional nature of the object when viewed from different network nodes

- The division of labour and power structure with people working in different communities although part of the same collective

- Different rules applying to different communities

- The usage of tools in different activity systems

\section{The transitional object, different communities and different rules}

At the design meetings and in the questionnaire it was repeatedly pointed out how the interest of members is the major focus of shop stewards' work. This overall object is shared by the entire LO organisation. As a union leader puts it:

There is a vision...that of course is built on the good work...it says so in the second paragraph of our regulations...we are to see to it that members have a good social situation, a good work situation, that they have an influence on society...

However, when retreating to the concrete instances of the overall object, its transitional nature becomes tangible. When talking to different people in the organisation, it becomes clear that the object manifests itself differently depending on function and level [25]. At the department level, operative instances are subdued and replaced by an administrative perspective. At the affiliation offices long-term interests become central. These perspectives are not always compatible. Instead, they display inner contradictions that lead to recurring breakdowns. Shop stewards report that the administrative perspective sometimes contradicts them in performing their tasks. They face bureaucracy and no direct means of solving urgent problems when they seek support. It is sometimes hard to get in touch with the right person. Likewise, leaders at the affiliation offices acknowledge that shop stewards find it hard to relate to longterm goals and strategy when working with day-to-day tasks [25]. Sometimes, even short- and long-term interests are incompatible. For instance, the local level often wants to negotiate at individual workplaces, hoping to secure a better outcome, while the management level recognises the benefits of central control 
and collective solutions [27]. This contradiction was manifest already in the middle $20^{\text {th }}$ century, when collective agreements emerged as a potential threat to local deals [27]. The contradiction becomes further manifest in that local shop stewards actually belong to parallel organisational structures [28]; two communities simultaneously, the workplace/company and the LO collective, whose interests do not always coincide, which may create double loyalty for shop stewards. The perceived contradictions are a result of people working in a large organisation that has its foundation on a common object, but where the object is loosely formulated and can take on different forms depending on where in the organisation one belongs. Different people live in different subcommunities making up the larger union community. These are, in turn, governed by different rules that are sometimes incompatible.

\section{Labour division and power re-produced in the usage of tools}

The perceived contradictions are, furthermore, a result of the LO organisation being characterised by a marked labour division and inherent power structures. Work tasks are related to functions that lead to an alienation from those tasks that people do not work with directly. Shop stewards work with very concrete, daily problems at the workplace where they also have their ordinary jobs. Those working at the departments and affiliation offices are mostly full-time employed ombudsmen that have less contact with the daily reality of shop-floor work. Union leaders at the affiliation offices report that this has caused alienation and resulted in shop stewards experiencing a lack of understanding when they contact higher instances in the organisation [25]. Further, power increases with the advancement of level in the hierarchy and the power of shop stewards is limited. For instance, they do not participate in central negotiations and cannot decide on educational issues for themselves and members. At the design meetings, it was acknowledged that:

Access to information increases the higher up in the organisation you reach, and...does not automatically imply that you are allowed to distribute it downwards.

The power structure is also reproduced in the information technology tools that different levels use. Computer access is often restricted for shop stewards at the workplace. Most often, shop stewards still have to visit the sections or departments if they want to access union information systems and applications. Even here, they cannot access everything but systems are divided into closed (e.g. intranets), half open (e.g. the study systems) and open systems (e.g. the affiliations' home pages). An apprehension sometimes held among shop stewards is that information gets stuck on the way and is filtered by the middle union levels. Shop stewards most often do not have the right to contribute their 
own material to the systems [25]. The networked activity systems and their contradictions are shown in Fig. 4.

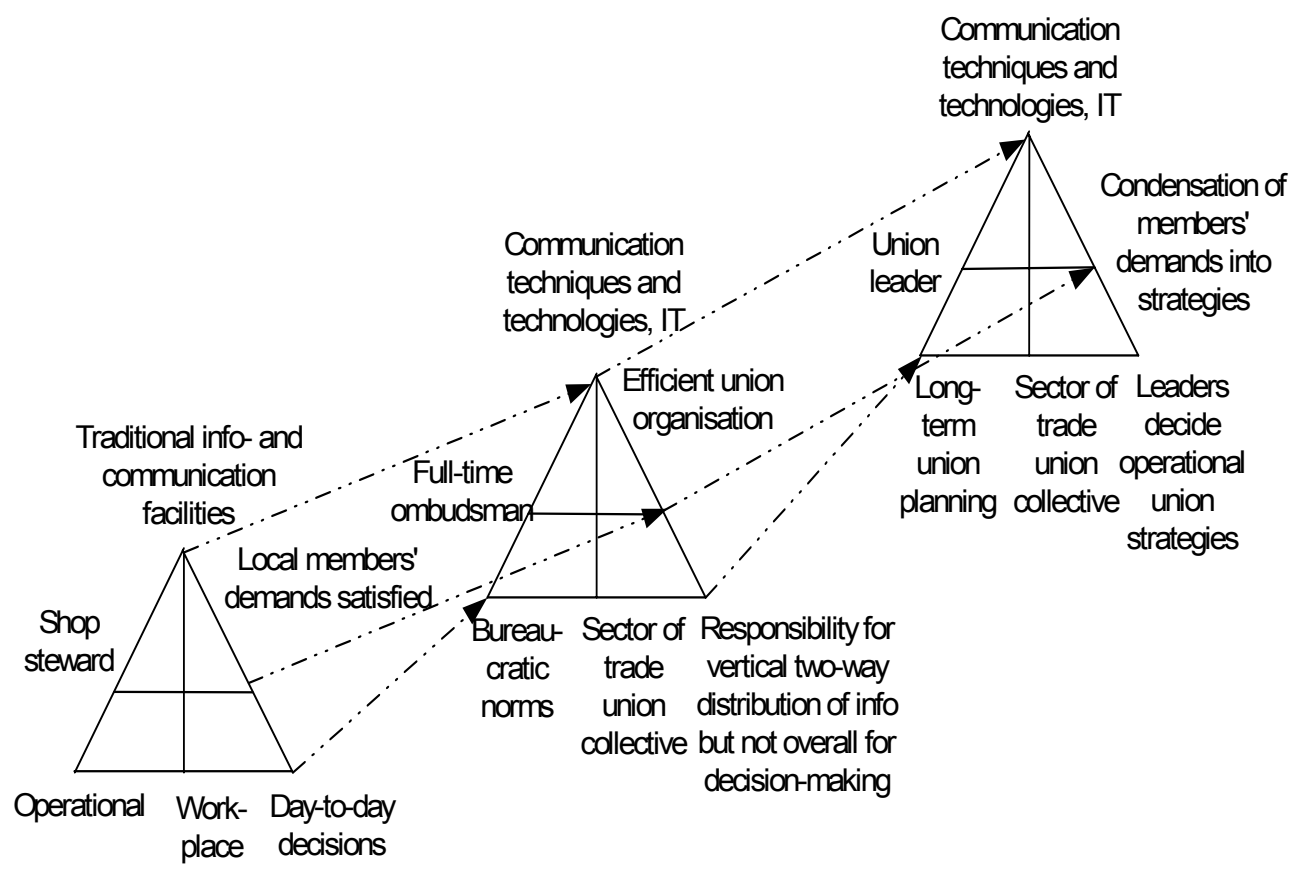

Figure 4. Contradictions in the object, rules and use of tools between different activity systems. The contradictions are described from the viewpoint of shop stewards.

\section{Towards the collective local union subject}

The introduction of new technology can lead to the establishment of a zone of proximal development in the activity system of shop stewards. Consequences may relate, not only to the activities and their object, but even to the nature of the subject itself. The potential consequences emerging from the data analysis can be summarised in terms of emancipatory mediation of interpersonal relations characterised by high social value, allowing the shop steward community to form a significant new collective subject (Fig. 5):

- As shop stewards' object of work expands, they will be able to perform certain tasks previously carried out higher up in the LO organisation.

- Local communities of shop stewards will be formed and the larger union community will become less visible.

- Some tasks of full-time ombudsmen will disappear and new ones will emerge. Ombudsmen may receive more supervisory than direct support tasks, and administrative work will take on a new character.

- The local organisation will be strengthened, at the expense of either the middle union layers or the LO management level. 
- The boundaries of the individual union affiliations will be either weakened or strengthened, depending on which system facilities shop stewards prefer to use.

Introducing an extensive information system that is explicitly designed for shop stewards tasks will, if it is frequently used, certainly influence and perhaps even radically transform the tasks. Below, the prototype which emerged from the data collection and design work is briefly described and the potential consequences of its implementation are outlined. The prototype is a web-based solution that is intended to be compatible with already existing systems in the union affiliations. Much of the information is supposed to be stored by central LO but downloadable for the affiliations so that they can integrate it with their own information and web-sites. Some communication facilities are, however, affiliation comprehensive. The prototype is entirely or partially implementable. It is structured hierarchically, with separate entries to central LO, the affiliations, departments and workplaces, depending on user belonging.

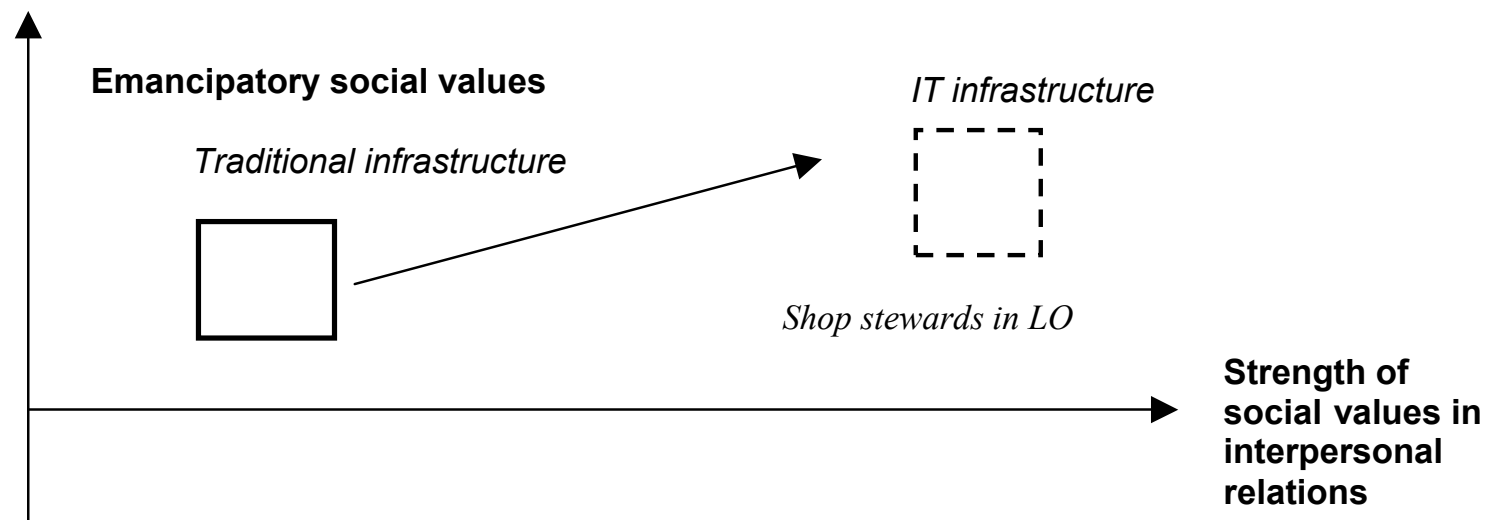

Antisocietal social values

Figure 5. Anticipated changes for shop steward subjects in the union community following introduction of new IT infrastructure with respect to the nature and strength of mediation in interpersonal relations.

\section{Mediation of interpersonal relations with high social value}

Implementing the system is intended to result in changes in the activity system of shop stewards as well as in the networked activity systems (Fig. 6.). In the prototype, several communication facilities that will have an impact on the mediation of interpersonal relations are included. 
Tool:

Communication techniques and technologies, IT
Tool:

Communication techniques and technologies, IT

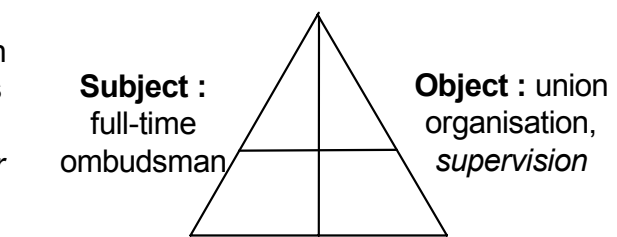

Rules: a new Community: Division of labour: administration with sector of only partial decreased trade union responsibility for bureaucracy collective distribution of info, available for shop stewards when needed

Tool: collective

bargaining, IT

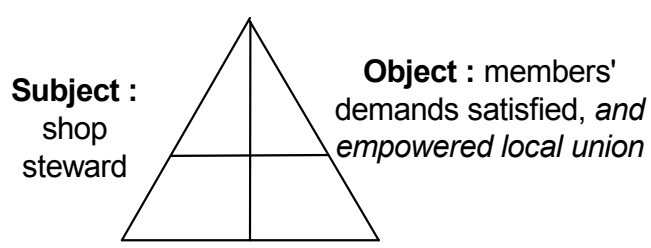

Rules: legislation, union strategies

Community: Division of labour: workplace, day-to-day decision shop steward making, collaboration networks among shop stewards

Figure 6. The future activity systems in the union organisation. The envisioned changes are italicised.

\section{Cross-union horizontal communication facilities}

The system will promote horizontal, in- and across union communication facilities, e.g. discussion forums, NetMeeting, and chat rooms. Shop stewards should be able to share experiences with each other, both within and between affiliations. Communication at the local level should be encouraged, and shop stewards should be able to create their own discussion groups. Filtering mechanisms will be provided so that the users can search, e.g. by subject and vocation, to find persons with similar background. The system will also promote an exchange of data files and document sharing on-line. Also vertical communication facilities will be provided, but in the main, horizontal communication is emphasised. Today, contact between shop stewards is experienced as strikingly insufficient. 


\section{Local profile and international contacts}

The planned system will have a local profile. When the shop stewards log in they should recognise the logo of their respective affiliation, and the default value for sections and departments will be set to those they belong to. The entry page should reflect the access profile the user has. Access to some discussion forums will be co-ordinated, e.g. according to department belonging. Meanwhile, even contacts above the local level will be encouraged, e.g. through cross-union mail lists and large discussion forums. In addition, links to international union affiliations and corresponding affiliations in other countries will be provided, in order to enhance possibilities for cross-national and cultural contacts.

\section{Cross-union contacts and power re-distribution}

Introducing explicit facilities for horizontal communication among shop stewards will have consequences. People belonging to the local level might contact each other instead of turning upward in the LO organisation, especially in cases in which they report that they experience insufficient support. In the long run, new sub-communities of shop stewards working with the same tasks, having similar vocations, or belonging to affiliations of a similar character may be formed. Shop stewards may become increasingly independent of the larger union community, as they are able to solve problems within their own subcommunities. This implies empowerment, a strengthening of the local level, and far-reaching consequences for the entire organisation. Research has shown that the early adopters of new technology are those who most often reinforce their position in the organisation [29]. In this case, the shop stewards would be the primary users. The inner contradictions between their activities and those surrounding them may be further perceptible and result in fundamental changes. For instance, a return to more negotiations taking place at the local shop-floor level may become accentuated, i.e. a kind of cyclic retreat to the activities which dominated early $20^{\text {th }}$ century shop steward work. This, in turn, can have several possible consequences. If the sub-communities become increasingly stabilised, it can either result in that the central affiliation and thereby the entire LO management level loses power as strategies and decisions increasingly reside within the new communities. It can also result in that the middle layers are weakened if their tasks become superfluous. Research has shown that the introduction of new technology to organisations often promotes direct contacts between the bottom and top layers, skipping those in between [30]. Shop stewards may turn directly to the top management level, if equipped with direct communication facilities. Either way, the layers above the local level, if they provide shop stewards with a do-it-yourself characterised information system, run the risk of undermining their own position. 


\section{Shop steward independence and emancipation}

The system includes several information sources aimed at increasing shop stewards' independence and potential to manage their tasks.

\section{Case based information (peer support)}

The planned system is intended to include case based information as a complement to the fact based, e.g. laws and agreements that exist today. Shop stewards are to submit real examples from negotiations or other problem situations to a database, so that the experience can be shared among them. A moderator is to deal with issues of anonymity and the avoidance of personal offence.

\section{Templates, forms, and external links}

Templates and forms that can support some of the tasks of shop stewards will be available. These can be used, e.g. when writing resolutions, budgets, and letters to authorities. Further, links will be provided so shop stewards can navigate to the sites of authorities that they sometimes have to contact in their work, e.g. the National Social Insurance Board. Today, many of these contacts are taken via sections and departments. Finally, the system provides easy access to several online dictionaries and encyclopaedias that can serve as tools for the inexperienced writer.

\section{Expanded possibilities for continuous education}

One intention behind DLK is to use information technology for distal, interactive, continuous learning education integrated with day-to-day union work. The system will include on-line courses that can be reached by a larger number of shop stewards. Further, the training content will be expanded, from a focus on fact- based union information to include the development of personal skills for work and life in general. Shop stewards are to be able to create their own study profile. The system also includes a database with information on different courses provided by LO, its affiliations and departments.

\section{Services for promoting the union}

Today, the LO organisation provides a wide range of member offers that is not explicitly related to work life, e.g. loans, insurance policies, vacation offers, and cultural events. However, both the affiliation offices and the shop stewards, themselves, recognise that they have incomprehensive knowledge the existence of these offers, so that they seldom reach members [25]. At the design meetings it was frequently mentioned how the unions deal insufficiently with marketing themselves, thereby losing members. Therefore, information on these services will be included so shop stewards can be better equipped for promoting the union. 


\section{An expanded object of shop stewards' work and a changed division of labour}

The system will have a self-supportive character. At the design meetings, it was requested that when questions are sent to the sections and departments, they should not provide an answer, but refer to sources in the system. This also means that shop stewards will face increased demands with regard to responsibility and evaluation of material not interpreted by higher organisational levels. Their role as promoters of the union may become more emphasised. In other words, the object of shop stewards' work, although remaining the same in overall form, will expand concretely. Their continuous knowledge acquisition will be more emphasised and the role of evaluators and marketers will be added to those previously outlined. Potential consequences will likely stretch beyond these activities to other parts of the organisation. The supportive functions of the sections, departments, and affiliation offices might be de-emphasised. Some tasks of full-time ombudsmen, e.g. answering questions, guiding shop stewards to agreements and helping them interpret them, may become partly redundant. On the other hand, the scenario of a working system implementation requires that shop stewards initially be provided with "help to self-help" on how to retrieve, filter, and evaluate relevant material. Further, the system needs to be administered, a function which will most likely reside with the departments. This includes continuous updating, and web-master functions. At the design meetings it was suggested that the sections and departments should have the mandate to correct potential erroneous information that has been submitted, and also check suggested links for quality. A potential outcome will, thus, be that the administrative character of these levels will become less accentuated, and that supportive tasks will partly be replaced by supervisory tasks. This, in turn, puts new demands on the skills of those working; some people may become redundant and new competencies will be needed. On the other hand, information technology calls for a new form of administration in which bureaucracy and protracted routines will not suffice if the system is to stay alive. As acknowledge by one person at an affiliation office:

If we make this new information technology investment...new competencies perhaps non-existent in the present organisation, will be needed...IT skills are needed but even traditional ones...you have to mix old and new and everything will happen at a much faster pace...

Another issue is related to the future role of the individual union affiliations; the system will include facilities for retrieval of both internal- and cross affiliation communication and information. Thus, possibilities both for the strengthening and weakening of affiliation boundaries are built in. What will happen will eventually depend upon which facilities are mostly used. It is, however, clear 
that the system introduces new possibilities for the forming of union networks, that may result in constellations between affiliations, and in the individuality of affiliations being less marked. On the other hand, since in the present prototype version, much of the information is provided by LO via the affiliations, these may choose to let this information reflect their own affiliation rather than the entire collective.

\section{Discussion}

It has been claimed that the potential of Activity Theory in system development must be demonstrated in practice, in concrete projects $[9,15]$. In this study, an Activity theoretical framework was used to map out the potential consequences of implementing an extensive information system in a national union confederation. The hypotheses assume an ideal situation in which all shop stewards access and use the system for its intended purposes. Much remains to be seen whether the implementation will have the effects outlined. Future studies will include the investigation of information technology facilities use and organisational effects in one of the individual affiliations. The system's local and self-supportive character is based on shop stewards' needs and on the motivation behind the entire project. But, also the voices of departments and affiliation offices, and central LO, have been given due attention in the design. The final solution will be a compromise that is based on the needs of shop stewards but will also show consideration for to the other LO organisational levels.

\section{Experience from the study - towards a renewed Activity theoretical framework?}

In the effort to investigate the challenges that come with applying MAT to the context of designing a comprehensive information system for an entire organisation, the experience from this study is that MAT can be applied with a wider organisational perspective, and also that it can bring major benefits to system development. Organisational changes, of course, correspond to which facilities information systems include. MAT is useful in helping foresee potential consequences of system implementations, and in investigating how different design solutions might change an organisation. For instance, in the case of LO, the marked self-supportive character of the system, and the fact that it provides entirely new facilities for communication among shop stewards, will probably affect the organisation more, than if only previously existing 
information sources had been computerised. MAT provides a framework that assists in structuring and providing an overview of the entire organisation, thereby, reducing the risk that certain levels or groups are overlooked. In this study, it was used to connect the activities taking place at union departments and affiliation offices with the activity system of shop stewards so that design focus also embraced the higher LO organisational levels, for the purpose of reaching a design solution accepted by the entire organisation. Even if merely hypotheses can be formed at this stage, these are an aid for designers in seeking the best possible solutions that can benefit the organisation. Some design solutions are sometimes unacceptable since they break too radically with existing structures and norms. Here, it appears that MAT can support in avoiding these solutions, which too often lead to information systems remaining unused. In this study, it was for instance found that some tasks, as a consequence of history, tradition and culture, ultimately reside with the ombudsmen and will not likely be transferred to the shop stewards. The original design of a course database, where shop stewards could apply for certain courses has been rejected both in the design group and at a prototype evaluation. The reason was that this solution would take important tasks from the study ombudsmen at the departments. However, using MAT in this context is not without difficulty. Davidov [19] has recently pointed some problems with Activity Theory, e.g. related to structure of activities and an unclear distinction of individual versus collective subjects. Also the overall organisational approach taken in this study poses several questions that need to be considered.

\section{The evasive object}

Even when applying MAT at a detailed level, distinguishing between objects, activities, sub-activities, tasks, and operations is sometimes problematic. The theory provides mere guidelines and much is left to the assessment of the researcher. When applying MAT in an organisational context, the object becomes increasingly abstract and evasive. It was first found difficult to describe the object at a general level and then distinguish between that and its concrete instances. Is it for instance possible to say that the object of shop stewards' work is to fulfil the daily needs of members, and that this differs from the ombudsmen who have more long-term responsibilities? Where do you draw the line between different objects and their different manifestations? Is there a change in the notion of an object when looked upon from the perspective of an entire organisation? How can we distinguish between overall, officially acknowledged objects and the more manifest, immediate objects of those working?

\section{Activities versus practices}

Furthermore, it was difficult to break down overall activity systems and to determine the major activity, what are the practices, and where do we leave 
them for the corresponding action level. One experience is that the overall activities taking place in an organisation need to be described at a more general level than when studying individual activity systems as parts of an organisation. The leap to the action level then becomes huge, e.g. between satisfying the needs of members and actually making a phone call. It was, therefore, necessary to introduce the intermediate level of practices, e.g. carrying out negotiations. A question is whether or not this practice level corresponds to the activity level when applied in a more individual sense, and how we should treat the notions of activities versus practices and actions in an overall organisational context.

\section{People belonging to different communities}

Describing communities also became difficult from an organisational perspective. For instance, a shop steward is part both of an immediate workplace community and of the larger union community, both of which have an influence on his or her work tasks. In fact, in most organisations, there are several layers of both formal and informal parallel structures that people belong to [28, 31]. This factor, as well as the possibility of relating these communities to each other, are issues that should be taken into consideration.

\section{The nature of the subject}

In the present version of MAT, little attention is given to the nature of the subject [19]. It is often presumed that the subject consists of a group of individuals sharing object, rules and so on. But in an organisational context, the subject becomes complex and may even be composed of a variety of individuals working in the same context but having different rules and objects. In the case of shop stewards, they are supposed to be an ethically constituted subject with ideological norms governing their activities. Still, shop stewards report that some of them take on the assignment out of self-interest. Consequently, a classification of the collective subject seems necessary.

\section{The networking of activities}

Problems include the extent to which subjects in different activity systems share objects and where they differ, to what extent the activity systems shared rules, when did people belong to different activity systems simultaneously and what are the actual relations between these factors. It was hard to illustrate this and seems to demand more of the triangle approach. For instance, all people belonging to the LO collective might be said to at least officially share union ideology rules. But when looking at the actual activities at the different organisational levels, other rules may in practice guide these to a greater extent. When can one activity be said to stand on its own and when is it merged into 
others? How do we deal with the fact that people often belong to several activity systems? How do we mentally and visually connect these systems?

\section{Generalisation}

When describing an entire organisation in MAT terms it becomes necessary to generalise. It is easier to investigate the activity system of one single category of subjects performing certain well-defined tasks, than to investigate that of a diverse, heterogeneous group performing multiple tasks. In the latter case, it is more common with exceptions. The question is then whether or not the established picture is sufficiently valid.

\section{Computer support for shop stewards: critical issues remaining}

Two still unresolved issues with regard to computer support for shop stewards are, first, the willingness to implement the different parts of the system on the part of the union affiliations, and second, the actual usage of the system. Research has shown that management attitudes towards a system have a significant impact on actual usage by end-users [32]. In the project, hesitance has been expressed on the part of the affiliations as regards, e.g. the possibility for shop stewards to read and submit cases to a case database, and for shop stewards to have far-reaching access to the study parts in the system. As to the actual use of the system, this will greatly depend upon the extent to which shop stewards are willing to learn it. Much union work is done on a voluntary basis. This voluntary work might expand initially. The question is whether shop stewards have or will invest their time, and how much they are able to acquire in terms of new roles without it resulting in a work overload. The question is also whether or not they will use the system for its intended purposes. In the DLKproject, experience from the use of discussion forums in local projects show that communication relates to other union topics rather than the projects themselves, which were the intention of the forums.

Moreover, the design meetings and data analysis clearly show that the final system solution should stretch to include members as well. At the design meetings, it has been explicitly requested that members should have access to parts of the system, e.g. templates, certain bulletin boards and discussion forums. The next prototype version will, therefore, include three interfaces, one for the public, one for LO members and one for shop stewards. If the union members are also to access the system, this factor will have additional implications for the organisation, in particular, as regards the re-distribution of tasks and power among shop stewards and members. 


\section{Conclusion}

Even though macro-level Activity Theory attempts to move above the individual level, it tends to look at activity systems in parts of organisations, displaying individual or limited groups of subjects [16]. This study moved one level further by applying MAT to the analysis of an entire organisation and how it may be affected by an information system. The finding is that using MAT from an overall organisational perspective accentuates the difficulties connected with applying the theory. Problems relate to the abstraction of the object, distinguishing between activities and practices, people belonging to several communities simultaneously, the forming and visualisation of networked activities, the nature of the subject, and to generalisation. These challenges call for an expansion of the approach, above all, a reconsideration of what the different terms imply when used in this context. Perhaps loose guidelines should be provided. Still, using MAT in the context of system development for entire organisations was deemed as providing great benefits to the process, e.g. in terms of foreseeing potential consequences of the implementation of design solutions, and in investigating how different design solutions might transform the organisation. MAT provides a framework for structuring and providing an overview of an entire organisation, thereby, reducing the risk that certain groups of people are overlooked. Subsequently, the chances that new tools will be used beneficially are enhanced.

\section{Acknowledgements}

This study was financed by the Swedish Foundation for Development of Competence in the information technology domain (KK-stiftelsen). The authors wish to thank Yrjö Engeström and Sara Jägare for providing useful comments on this paper.

\section{References}

1. Kuutti, K. (1996) Debates in IS and CSCW research: anticipating system design for post-fordist work, in Humane Interfaces: Questions of Methods and Practice in Cognitive Psychology (Orlikowski, J., Walsham, M., Jones, J. and DeGross, J., eds.), Chapman \& Hall, London, pp.287-308.

2. Iansiti, M. (1998) Technology Integration: Making Critical Choices in a Dynamic World, Harvard Business School Press, London. 
3. Kuutti, K. (1995) Activity Theory as a potential framework for humancomputer interaction research, in Context and Consciousness: Activity Theory and Human Computer Interaction (Nardi, B., ed.), MIT Press, Cambridge, pp.17-44.

4. Jayasuriya, R. (1999) Managing information systems for health services in a developing country: a case study using a contextualist framework, International Journal of Information Management, Vol.19, No. 5, pp.335349.

5. Engeström, Y. (2000) Activity Theory as a framework for analyzing and redesigning work, Ergonomics, Vol. 43, No. 7, pp.960-74.

6. Virkkunen, J. and Kuutti, K. (2000) Understanding organizational learning by focusing on "activity systems", Accounting Management and Information Technologies, Vol. 10, pp.291-319.

7. Virkkunen, J., Engeström, Y., Helle, M., Pihjala, J. and Poikela, R. (1996) The change laboratory - a tool for transforming work, Lifelong Learning in Europe, Vol. 1, No. 2, pp.10-17.

8. Hasu, M. and Engeström, Y. (2000) Measurement in action: an activitytheoretical perspective on producer-user interaction, International Journal of Human-Computer Studies, Vol. 53, pp. 61-89.

9. Kuutti, K. (1999) Activity Theory, work, and systems design, in Perspectives on Activity Theory (Engeström, Y., Miettinen, R. and Punamöki, R., eds.), Cambridge University Press, Cambridge, pp. 360-376.

10.Engeström, Y. (2001) Expansive learning at work: toward an activity theoretical reconceptualization, Journal of Education and Work, Vol. 14, No. 1, pp.129-152.

11.Leigh Star, Susan, Working together: Symbolic interactionism, Activity Theory and information systems, in Cognition and Communication at Work (Engeström, Y. and Middleton, D., eds.), Cambridge University Press, pp. 296-318.

12.Engeström, Y. (1987) Learning by Expanding. An Activity-Theorethical Approach to Developmental Research, Orientat-Konsultit Oy, Helsinki. 
13.Engeström, Y. and Miettinen, R. (1999) Introduction, in Perspectives on Activity Theory (Engeström, Y., Miettinen, R. and Punamöki, R., eds.), Cambridge University Press, Cambridge, pp. 1-16.

14.Engeström Y. (1999) Expansive visibilization of work: an activity theoretical framework, Computer Supported Cooperative Work, Vol. 8, pp.63-93.

15.Hasan, H. (2001) An overview of different techniques for applying Activity Theory to information systems, in Information Systems and Activity Theory: Volume 2, Theory and Practice (Hasan, H., Gould, E., Larkin, P. and Vrazalic, L. (eds.), University of Wollongong Press, pp. 3-21.

16.Ellison, M. and McGrath, G. M. (2001) Business process modelling using Activity Theory: an approach to data capture and analysis, in Information Systems and Activity Theory: Volume 2, Theory and Practice (Hasan, H., Gould, E., Larkin, P. and Vrazalic, L. (eds.), University of Wollongong Press, pp. 143-172.

17.Christiansen, E. (1996) Tamed by a rose. Computers as tools in human activity, in Context and Conciusness. Activity Theory and Human-Computer Interaction ( Nardi, B., ed.), The MIT Press, Cambridge, MA, pp.175-198.

18.Engeström, Y., Engeström, R. and Vähäaho, T. (1999) When the centre does not hold: the importance of networking, in Activity Theory and Social Practice: Cultural-historical Approaches (Chaiklin, S., Hedeggaard M. and Jensen, U. J., eds.), Aarhus University Press, Aarhus, pp.345-374.

19.Davydov, V. V. (1999) The content and unsolved problems of activity theory, in Perspectives on Activity Theory (Engeström, Y., Miettinen, R. and Punamöki, R. eds.), Cambridge University Press, pp. 39-52.

20.Reynolds, M. O. (1998) The prospects for right to work, Journal of Labor Research, Vol. 19, No. 3, pp.519-528.

21.Sandberg, Å., Broms, G., Grip, A., Sundström, L. and Ullmark, P. (1992) Technological Change and Co-determination in Sweden, Temple University Press, Philadelphia.

22.Pilemalm, S., Hallberg, N. and Timpka, T. (2001) Organisational policy and shop-floor requests in design. Visualisation of the argumentation behind an information system for the Swedish trade union movement, Scandinavian Journal of Information Systems, Vol. 13, pp. 7-30. 
23.Johansson, M. C. G. (1999) Social and Organizational Aspects of Requirements Engineering Methods. A Practice-Oriented Approach, Linköping Studies in Science and Technology, Dissertation No. 594, Linköping.

24.Petrovsky, A. V. (1986) Collective, in Psychology (Volkov, F. M., ed.), Progress Publishers, pp. 177-189.

25.Pilemalm, S., Hallberg, N. and Timpka, T . (2000) From UTOPIA to DLK management of external voices in large participatory design projects, in Proceedings of the Partcipatory Design Conference (Cherasky, T., Greenbaum, J., Mambrey, P. and Kaaber Pors, J., eds.), CPSR, Pao Alto, pp.56-65.

26.Pilemalm, S., Hallberg, N. and Timpka, T. (2001). How do shop-stewards perceive their situation and tasks? Preliminaries for support of union work, Economic and Industrial Democracy: An International Journal, Vol. 22, No. 4, pp. 569-599.

27.Nyström, Ö. (2000) Mellan anpassning och motstånd - Facket och det nya arbetslivet. [Between Adaptation and Resistance - The Unions and the New Working Life], Atlas bokförlag.

28.Westlander, G. (1999) People at Work. Investigating Social-Psychological Contexts, Studentlitteratur, Lund.

29.Burkhardt, M.E. and Brass, D. J. (1999) Changing patterns or patterns of change: the effects on a change in technology on social network structure and power, Administrative Science Quarterly, Vol. 35, pp.104-127.

30.Davenport, T. H. (1993) Process Innovation-Reengineering. Work through Information Technology, Harvard Business School Press, Boston.

31.Porras, J. I. and Robertson P., J. (1992) Organizational development: theory, practice and research, in Handbook of Industrial and Organizational Psychology (3) (Dunnette, D. and Hough, L. M., eds.), Consulting Psychologists Press, pp. 719-741.

32. Ghorab, K. E. (1997) Impact of technology acceptance considerations on system usage and adopted level of technological sophistication: an empirical investigation, International Journal of Information Management, Vol. 17, No. 4, pp.249-259. 
Using Activity Theory in System Development for Entire Organisations - the Case of the Swedish Trade Union Confederation 